\title{
Responsibility as the Welcoming of Difference: Thoughts on Levinas and a Teacher's Experience
}

\author{
Tim Molnar \\ University of Saskatchewan
}

\section{Author Note}

A previous form of this writing called "Welcoming as a Language for Understanding Pedagogical Responsibility” was presented at the CSSE Conference, May 2009, Ottawa, Canada.

Correspondence concerning this article should be addressed to Tim Molnar, College of Education, University of Saskatchewan, Saskatoon, Saskatchewan, S7N 0X1 Email: tim.molnar@usask.ca

\begin{abstract}
This work interweaves a discussion of the philosophy of Emmanuel Levinas and the experience of an educator working in a cross-cultural context, to provide an opportunity for the reader to reconceive the idea of responsibility. Through this article, I develop the idea that responsibility can be understood as a welcoming of difference where a "language" of interruption, vulnerability, hospitality, and learning from the other exists. The notion of welcoming is offered as complimentary approach to other arguments advocating the necessity for educators to attend to anti-racist and social justice issues and perhaps offers another answer to doubts concerning the involvement of educators.
\end{abstract}

Keywords: Levinas; cross-cultural; education; social justice; anti-racism 


\section{Responsibility as the Welcoming of Difference: Thoughts on Levinas and a Teacher' Experience \\ Words of Welcoming}

A bold grade nine student asked me,

"Why another White teacher...

This was supposed to be a First Nation school?”

Five student funerals in less than six years of teaching.

That does not include the two I attended this fall...

Something is wrong with this picture!

Did I want to consider my White privilege?

To challenge my

common sense understanding,

comfortable practice, and

work ethic belief...

that all people have access to the

dominant social structure

It took the student discourse as Other

to reveal and deconstruct

my discourse,

my worldview,

in order to create authentic meeting opportunities

in the classroom and out

The existing pedagogy of decolonization serves

to further stereotypes and

not to challenge the dominant cultural system

keeping the "familiar" First Nation narrative

First Nation students implicitly learn their place in the cultural system as an additive other. ${ }^{1}$

The words above, spoken by a teaching colleague, prompted me to think about what is involved with responsibility as I welcome people to learn. I wondered if her words and a different consideration of welcoming might provide some insight for us as educators in better understanding our relationship with and responsibility to others. Attention to such relationship is important, but perhaps especially so in contexts typified by ethno-cultural difference where the need for anti-racist and social justice work exists, yet where some educators may be reluctant or unconvinced about the necessity to examine their perspectives and take action.

Evidence for the necessity of such examination and involvement has been detailed by various writers (Blades, Johnston, \& Simmt, 2000; Kumashiro, 2000, 2001; Labelle \& Ward, 1994) and very specifically in regards to First Nation and Métis experience in contemporary 
educational contexts (Battiste, 2000; Battiste \& Barman, 1995; St. Denis, 2009). White (2010) suggests the challenges for educators to be active in such work will only get more pressing and challenging, for, as Todd (2007) notes, there exists "the difficulty of judging what is just in the context of an increasingly divergent public - and classroom-discourse about values, rights and equality” (p. 27).

Given the realities and challenges people of Aboriginal heritage continue to face in participating in contemporary Canadian schooling, where there is the demand for people "to become something more than themselves" (Britzman, 1998, p. 10), it is hard to imagine there would be much argument concerning an educator's responsibility to help people meet these challenges. As St. Denis (2009) points out, the need for a critical anti-racist education and the involvement of non-Aboriginal educators is vital, yet educators may eschew such work or hamper the process in a variety of ways.

There is another challenge that emerges as well, for in attempting to benefit particular groups through social justice and anti-racist activities, there remains the need, as Biesta (2003) suggests, for safeguarding the uniqueness of others - where individuals are not seen only as a particular instance of something more general. Here perhaps, in following Levinas (1981), readers will encounter ideas about responsibility and humans as ethical beings that may change their thoughts and prompt new action. Regardless, if the focus is on a group or an individual, or on what is ethical or just, there remains a need for people to "think differently, [so they] can change the way they relate to each other, and can form new understandings of themselves and the world that makes possible the very act of teaching and learning” (Todd, 2001, p. 435) — where there is need to rethink responsibility (Todd, 2003, 2007, 2008).

With such ideas in mind, I am suggesting the philosophy and writings of Emmanuel Levinas $(1961,1981)$ may be helpful for those who encounter reluctance in others to undertake anti-racism and social justice work. What might be relied upon in provoking involvement in others is Levinas's ideas; he offers a radically different perspective on responsibility — one that in a manner leaves no place to hide.

I hope by coupling aspects of Levinas's thinking and that of other writers, such as Todd, along with an educator's experience of realizing his or her responsibility, in this case a teacher named Faith (pseudonym) whose words are encountered above, might gain insight into our responsibility as educators and as human beings. I am suggesting that we as educators consider responsibility as a welcoming of difference that has a particular "language" or "vocabulary" which we "speak" and which "speaks us." To better understand what this welcoming and language of responsibility might be, some foundational aspects of Levinas's thought must be briefly considered.

\section{Levinas}

Some writers concerned with ethics and education suggest that if discussions turn to topics such as responsibility, Levinas's work warrants consideration (Egéa-Kuehne, 2008). Levinas's thoughts are shaped by his experience as a Lithuanian Jew, a speaker of several languages, a person who lost family members in the Holocaust, an academic, and a war veteran (Hutchens, 2004). Relying on Levinas is a challenging prospect because his ideas often appear removed from everyday circumstance and language usage, whereas Standish (2008) notes, “Levinas's (2008) work has been interpreted in a way that relies excessively on a vocabulary of transcendence, causing it to be rarified and detached from the quotidian circumstances of human lives” (p. 56). Like Standish, I am concerned with pragmatic outcomes and in this case this means offering an accessible understanding of the ethical aspects of human interaction. The challenge of Levinas's work remains. However, by relying 
on the experience of Faith, I hope my considerations of responsibility as a welcoming of the difference of others may become clearer and hopefully somewhat convincing, or at least useful. This interweaving is, in a manner, an opportunity to test if Levinas's ideas might be helpful_-admittedly a determination that in the end rests with the reader.

Levinas's ideas and writings do not offer specific procedures concerning ethical behavior and people who insist on this may miss the point of Levinas's fundamental interrogation of ethics and human relationship (Davis, 1996; Hutchens, 2004). Similarly, works such as Ermine's (2007) discussion of the "the ethical space of engagement" also offer an opportunity for consideration and discussion that is sophisticated and multifaceted, yet do not offer precise prescriptive points.

In both cases, one is ultimately left to formulate one's thoughts concerning experience, and is not provided with precise steps or rules regarding morals and ethics or responsibility. This is perhaps where the opportunity to gain insight into practical everyday experience resides. Reading the experience of a teacher such as Faith alongside Levinas's ideas can, I hope, put some "flesh on the bone" of such experience. But what does Levinas offer?

Levinas attempts to reframe what it means to be ethical, bringing into question the traditional grounds of contemporary ethics that emerge from the ontological foundations of the Western tradition. This ground most often relies on establishing rigid schemes, scientific claims, lists, and prescriptions regarding ethics and responsibility (Davis, 1996). For Levinas, as Hutchens (2004) notes, being ethical goes beyond a place where "everything must be known, understood, synthesized, analyzed, utilized; if something cannot be grasped by the rationalistic mind, then it is either extraneous or portentous”(p. 14). Ermine (2007) might identify this as the "brick wall of a deeply embedded belief and practice of Western universality" that is typified by "the dissemination of a singular world consciousness, a monoculture with a claim to one model of humanity and one model of society (p. 198). What Levinas's $(1961,1981)$ writings suggests is that such efforts to contain difference emerge from a Western ontology and are dangerously in error and require rethinking. What is at stake, whether one is concerned with social justice (Ermine) or individual responsibility (Levinas), is the possibility of denying the very real presence of others who are "what I myself am not" (Levinas, 1987, p. 83) and are irreducible "to the I, to my thoughts and my possessions (Levinas, 1961, p. 43).

Cohen (2000) suggests that "at the bottom of Levinas's thought is not the epochal power of being but the moral authority of human integrity" where "the flesh and blood self is mortal, suffers, and hence the I is responsible for the other. I am - to be a self is responsibility for the other" (p. 30). The implications of such thinking-where responsibility prefigures what is known and our very being-is a radical departure from Western philosophical thought. Levinas inverts the notion that "if we can know who we are we will then know how to be responsible" (Todd, 2003, p. 2), and instead offers that our subjectivity and ethical reality emerge in the presence of others and so are already indebted to them. To be, is to be already responsible not only for one's self, but also for others (Blades, 2006), where responsibility is "about surrender and openness to the other; about saying 'yes' to the otherness of the other; and about suffering through anxious situations not of our own making, but to which we are nevertheless called to respond”(Chinnery, 2003, p. 7). In such wording, one has to remain aware that Levinas's focus is on the face-to-face meeting of individuals.

Responsibility then, comes not as an afterthought of a singular being, where freedom is found in turning from others, but instead responsibility already exists in the presence of other human beings, arising from a "world of social relationships which we have not chosen 
and which we cannot ignore” (Hutchens, 2004, p. 19). Some of the implications of this I will offer later, but what is involved with understanding responsibility as a welcoming?

\section{Responsibility as Welcoming}

To approach the Other in conversation is to welcome his [sic] expression, in which at each instant he [sic] overflows the idea a thought [sic] would carry away from it. It is therefore to receive from the Other beyond the capacity of the I, which means exactly: to have the idea of infinity. But this also means: to be taught. The relation with the Other, or Conversation, is a non-allergic relation, an ethical relation; but inasmuch as it is welcomed this conversation is a teaching [enseignement]. (Levinas, 1961, p. 51)

In these somewhat cryptic words, there is the suggestion that encounters in conversation with other human beings are a welcoming of difference, an act that is inherently ethical. This passage allows consideration of what welcoming involves in ways that move beyond typical understandings of welcoming others. These words suggest that there is a vocabulary or language of welcoming that might aid one in thinking about responsibility.

There seems to be a language at play within Levinas's ideas, a language that exists in a person's embodied experience which is not typically thought of as language-where language is understood as a technical mode or tool of communication involving "rational principles or empirical information... a device that isolated individuals use to establish rapport and equal proximity between themselves and other people” (Hutchens, 2004, p. 47). There is perhaps with Levinas a language that originates in the expression of the non-verbal commands found in the face-to-face ${ }^{2}$ relationship with another person; commands in which the presence of another insists that no harm is done to them, and in which the other person is always more than and other than what they are thought to be (Levinas, 2000). As Wild suggests, in a preface to Levinas's writings, Levinas does not deny "that a great part of our speaking and thinking is systematic and bound by logic of some kind” (Levinas, 2000, p. 14), but before such order and systems, before language as language is typically conceived, exists the encounter with the human presence of others, where welcoming and communication are already present.

Derrida (1999) explores this further and locates the emergence of language as existing simultaneously with welcoming when he suggests,

Welcome cannot be derived, no more than face can, and there is no face without welcome. It is as if the welcome, just as much as the face, just as much as the vocabulary that is co-extensive and thus profoundly synonymous with it, were a first language, a set made of quasi-primitive — and quasi-transcendental—words. (p. 25)

If Derrida's suggestions are followed, that of welcoming as a "first language," what might be involved with these quasi-primitive and quasi-transcendental words of welcome? Welcoming as a first language, Todd (2005) suggests, "provides a discursive space of engagement, dynamically giving and receiving in the same turn" (p.15).

Drawing from Levinas (2000), Todd (2003) and Derrida (1999), I offer that this first language involves an interruption of self by the difference of others, where one's solidarity and sameness is shaken and undermined in encounters with others; vulnerability, where the self is already in transformation in response to infinite difference, independence, and moral ascendancy of others; and, hospitality, where difference is visited upon the self and is accommodated even as one struggles to retain one's place, role, or identity. Finally, there is one's learning from the other where the difference encountered teaches the self. If we as educators follow Levinas, these realities are significant realities that form our responsibility to others. 
If this is so, perhaps evidence of this language of welcoming can be found in the experience of people that in turn might help in gaining a different perspective on responsibility and so shape new actions. With this in mind, I offer the welcoming experience of Faith that offers an opportunity to reconsider responsibility and to offer an opportunity to gauge the usefulness of Levinas's ideas.

\section{Faith: A Welcoming Teacher}

Faith is a self-described middle-aged white woman who arrived in Western Canada from the United States. She taught at an inner city high school where the majority of students and their families self-identified as of First Nations or Métis heritage. She provided instruction in Language Arts, but also undertook other teaching assignments in subject areas such as wellness and psychology, and she organized various extracurricular school activities for students. Her experiences of struggling to navigate through the difference of others, in this context, were shared with me through reflective writings and conversation over several years. Her activities, along with our shared experience of teaching in this school as well as our collaboration on various activities, offer a degree of trustworthiness to what follows and lends credibility in how I employ the evidence of her words in considering responsibility as a welcoming of difference.

Faith's words seem to substantiate the notion of responsibility as a welcoming of the difference of others. Here, interruption by the difference she encounters awakens her to her "suburban privileged white experience"3 leaving her with a sense of being overwhelmed by the difference of students who were "brown, First Nations, and relegated to the place of Other by history and the practicing dominant Canadian white middle class" (Faith, interview, February 26, 2006). Her encounter with others different than herself left her questioning her role and the ethicality of her decisions where she was forced to consider her own culture and the culture of the students when a bold Grade 9 student asked her why was she hired to teach in this school? Why another white teacher, when this was supposed to be a First Nation school? Her expectations and assumptions, borne of her white privilege (Berry, 2007; MacIntosh, 1998), seem interrupted in her encounter with students. Her use of journaling and dialogue with students revealed to her how different her life and identity were from those of her students and how different their expectations were from other students she had known.

The interruption involved in welcoming seemed apparent where, for example, a student shared her experience of recovery from a spiral into drug abuse; abuse prompted by the student witnessing the murder of her mother by an uncle. Faith was unsettled as she encountered the stark reality of danger, racism, poverty, crime, and suffering experienced by this student and others, when she begins to realize that she "can't treat these students like kids. They are really young adults.” Faith continues,

They have seen more in their short years than I will ever see and they are mature in ways that other high school kids aren't. They are there at school because it is a safe place and that was something I started to notice. The whole purpose is completely different than any other high school that I had been in. (Interview, February 26, 2006)

This and similar statements seem to illustrate her vulnerability and how she learns what is needed of her in serving her students. In such interruption, a response forms and Faith appears to sense the need to learn the discourse of her students and what she later refers to as a need for "authentic meeting."

Faith's teaching efforts, assumptions, and expectations concerning students are unsettled. Her dismay at students' week-long absences, due to funerals or "cheque day," shows not only her disruption, but responsiveness, borne, if Levinas is believed, in 
vulnerability to others. She experiences, as Levinas (2000) suggests, the inability to surmount, envelop, or dominate the difference of other human beings. This is seen in her following statement:

My initial response to when kids were away for a week was to be really annoyed... "Didn't they understand the importance of school?” Because I was still in that taskoriented mindset... I started realizing this was part of the culture of students and that I can't change their culture; I can't change their experience...It would be like trying to hold back Niagara falls... To try and change all of the kids in the classroom so they are task oriented, achievement oriented, academic oriented; it wasn't working and it will not work. (Faith, interview, February 26, 2006)

Do Faith's words mean she believed that students could not learn or were incapable of learning? I do not think so. I think Faith means only that this situation would require her, as she says, "to figure out how to engage them, get them interested, and do things that would catch their imagination and feed into their reasons for being there" (Interview, February 26, 2006). In being interrupted, she can witness her vulnerability to others, where she enacts her responsibility in her encounter with difference.

Faith's words seem to convey a sense of the vulnerability found in welcoming. She was not merely with students - together yet basically unaffected and unquestioning - but she was also open to them, vulnerable to the difference she encountered and what that demanded of her. Her vulnerability seemed to involve moments where "to welcome the Other is to put into question [her] freedom” (Levinas, 1961, p. 85) where she encountered choices that were “incumbent upon [her] without any escape possible (Levinas, 1981, p. 13).

Faith's vulnerability to the needs of students is seen as she questioned herself and her motives; she asked, "Did I want to consider my white privilege, to challenge my common sense understanding, comfortable practice, and work ethic belief that all people have access to dominant social structure, my life?” (Faith, interview, February 26, 2006) These experiences of interruption and vulnerability seem interwoven and are part of how she attended to and was taught by the difference she encountered. Faith realized the need to get "past [her] middle class myths and [her] ignorance, to realize the culture of poverty is not synonymous with First Nation culture. It is an imposed culture. In Canada it happens to be the First Nations people in this oppressed place. The First Nations people did not choose it" (Faith, Interview, February 26, 2006). Faith's growing understanding is demonstrated when she says, "It took the student discourse as Other to reveal and deconstruct my discourse, my worldview and fields of reference, in order to create authentic meeting opportunities in the classroom and out." During the interview, Faith described her experience of five student's funerals in less than six years of teaching, not including the two that she attended in fall. Through this description, one can witness the interruption, vulnerability, and learning from the other that typify welcoming. These are moments of learning where she was, as she explains, "sponsored into the circle of mourning by the traditional elder I had come with....Something is wrong with this picture; teacher training did not prepare me to outlive students, to know how to grieve, or to know how to make sense of a classroom when I returned” (Faith, Interview, February 26, 2006).

These seem difficult lessons, when in the disruption of her assumptions and beliefs Faith learns responsibility in the interruption of her sameness and the taken-for-granted aspects of her world. This interruption occurs not so much from what emerges from any application of rules or guidelines she must attempt to enforce in her role as teacher, but perhaps from the unspoken demands placed upon her by the presence of students. Faith realizes she has a role in confronting "the existing pedagogy of decolonization [that] serves to 
further stereotypes and not to challenge the dominant cultural system that perpetuates this thought, keeping the familiar First Nations narrative” (Faith, Interview, February 26, 2006). Faith's enacted response involves altering how she implements curricula, reconstructing it to aid students in realizing the curricula's embedded white middle class assumptions, prerogatives, and language. She makes a concerted effort to help students develop skills in detecting and using the hidden symbols of power and language of the dominant culture in ways that are to their advantage, stating,

In the culture of check day, the culture of welfare, you are not going to learn the middle class hidden languages. You will know about them and how they oppress you but you are not going to know how to manipulate them to make them work for them. So I actually made that a conscious part of the curriculum with putting in the power of hidden language. (Faith, Interview, February 26, 2006)

In such instances, Faith contravenes some of the established norms and expectations for her role as teacher and in doing so opens herself for possible discipline. She is vulnerable not only to the needs of students and to what she believes she must change on their behalf, but also to possible repercussions from administrators, colleagues, and others. While these instances are evidence of interruption and vulnerability, they also attest to how the difference of others teaches Faith responsibility, as Todd (2003) says, building on Levinas's ideas, "I can be receptive and susceptible, I can learn from the Other as one who is absolutely different from myself” (p. 15).

Coinciding with learning from the other, interruption, and vulnerability is her experience of a hospitable welcoming, where the difference of others is experienced as "the Stranger who disturbs the being at home with oneself [le chez soi]" who "escapes [her] grasp by an essential dimension even if [one has] him at [her] disposal” (Levinas, 2000, p.39). In welcoming, Faith experiences hospitality, which involves the experience of the hôte or the person who is simultaneously a guest and a host in his or her circumstance. In welcoming, she finds herself welcomed, "sponsored in," to local First Nations social-cultural activities such as powwows, feasts, funerals, and round dances and this leaves Faith with a desire to belong but also brings further lessons, where she realizes,

I had finally started to be considered an insider. The kids were calling me Kokum ${ }^{5}$ and you know what an honour that is. To go from...well the first couple of years you are an outsider, and I always will be because I am white, with blue eyes, and I don't have the deep history that goes into this province, this land. As long as you don't have that you are always an outsider. You have to be invited to be on the inside...I know I truly don’t truly ever completely belong to First Nation culture... inclusion will be extended to me or not extended to me and when it is extended to me I feel like I belong. (Faith, Interview, February 26, 2006)

Faith realizes she can never fully accommodate the difference she encounters, nor be fully accommodated by others, even as she responds to being sponsored in, yet she accepts this and works with this sensibility. Derrida (1999) suggests of such instances, that there is an unavoidable and irresolvable tension, where one's role and position as a host is undermined even as one struggles to maintain such positioning in order to be the host. Living with, but better yet, thriving in the ambiguity of this tension is what Levinas believes signals the health of our ethical existence and responsibility as human beings.

In Faith's case she is a teacher inviting others in to her teaching context, yet is a stranger or guest in the broader landscape of history, culture, and place of those she welcomes. There is an association with others and their beliefs, values, and experience where 
she might find inclusion but never belonging. Faith was an outsider who lived to an extent as an insider, negotiating the tension of educating students of First Nation and Métis heritage and serving the needs of the local community culture, yet remaining fully aware that she was "white, with blue eyes" not having "the deep history that goes into this province, this land" (Faith, Interview, February 26, 2006).

Faith's experience seems to originate in a familiarity with and sense of being at home in mainstream schooling, a situation Faith described as involving the "dominant experience... of middle-class European understanding” (Interview, February 26, 2006). However, she feels out of place in her teaching situation and not entirely at home in the disruption of her imagined pedagogy. Faith encountered the difference of others that interrupted her solidarity signified in her phrases "urban post-colonial situation" and "First Nations culture.” In her encounter with difference, the norms of Faith's accommodation are discomforted and in the tension of this displacement the experience of hospitality or hôte existed.

The experience (or vocabulary) of interruption, vulnerability, and hospitality seem spoken by Faith in her welcoming of others. The readers can also witness how Faith is taught by the difference of others. Her words offer moments where the readers witness how she speaks the language of welcoming, but where welcoming also speaks her. This speaking involves a sophisticated and contextually unique understanding and enactment of responsibility that, according to Todd (2003), involves a search for the "capacity for a relationality not premised on control or coercion...[or]on denying or repudiating the student's needs” (p. 27). Whether Faith realizes or not, her responsibility involves enacting a noncoercive relationship or a less-wounding pedagogy. Her existence as an ethical being and her responsibility fundamentally involve a pacific relation to others borne in the welcoming of difference. This responsibility involves speaking the language of welcoming where she attends to her attending of others, listens to, and acts upon the dense plots of others' stories and lives (Todd, 2003).

\section{Closing}

What can be understood from Faith's experience and reading her experience against an understanding of responsibility as a welcoming of difference? There is much to be said; however, a few points strike me as especially cogent. First, one can think of Faith's experience of responsibility as an instance where she speaks the language of welcoming and that an important aspect of this is her attentiveness to the difference of others. Such attentiveness takes one beyond merely relying on rules, regulations, guidelines or even protocols which, though needed, will be insufficient guides to fulfilling one's responsibilities. The need to attend to the authentic relationship of human beings exists in responsibility and responsibility is not merely consigned to following one's duty or role, as seen with Faith. As Bauman (1993) and Todd (2003, 2008) suggest, there exists the opportunity to realize that responsibility cannot be covered over or avoided by interposing social, legal, or political interfaces between one's self and others, but that one's responsibility emerges in welcoming of the difference of others-a welcoming, however imperfect in practical terms, that provokes and challenges one to undertake the necessary tasks of understanding others and ourselves and taking action.

Second, considerations of welcoming as responsibility might provoke more direct thought about one's perceptions and offer a position from which to challenge the hegemony of contemporary Western perspectives on what is normative and ethical-a hegemony of universalism (Ermine, 2007) complicit in racist and oppressive practices. 
Finally, while ethicists such as Ermine argue for the need for the negotiation of an "ethical space of engagement" among communities, nations, and groups, one can ask what prompts people or provokes them to actually stand on the edge of this space, to remain there, to deal with the ambiguity and challenge this space creates, where they are "divided by the void and flux of their cultural distance" (Ermine, 2007, p. 24). There are powerful arguments that exist in advocating for educators' involvement in anti-racist and social justice undertakings, yet at the core of these exists how responsibility is understood and enacted in face-to-face interactions. The nature of these interactions rests on what responsibility is believed to be. If it is believed that freedom means the ability to turn from others, to be free from commitments to others, and that this is ethically sufficient, then involving others in the challenge of engaging the ethical space of engagement may be more challenging.

However, if people, both ourselves and others, can be convinced, that responsibility involves a welcoming of difference, that freedom is found in choices to aid, rather than turning from others, that there is already an existent and inescapable ethical relation, perhaps we can demonstrate to others that they are already irrevocably and inescapably responsible. They are on the edge of an ethical space of engagement and already involved in a negotiation, though they may feign otherwise. As Levinas suggests, one's encounters with others finds him or her already responsible.

Approaching responsibility as a welcoming helps to fashion further argument against the stereotyping and diminishment of others. We, as humans, are provided with a fundamental reality concerning the nature of the relations between human beings that does not allow us to turn from the others, to ignore their needs and the injustices they may experience. We realize the opportunity as St. Denis (2009) offers "to focus more attention on how to help our teachers to treat Aboriginal students like people” (p. 27), to be attentive to the difference of others.

What the notion of welcoming suggests to us as human beings and in our work as educators is that in whatever venues we operate or where ever we focus our energies, we have already been called to action on behalf of others and all already responsible. There is no question about if we are responsible. The immediate reality of how we are interrupted by the difference of others, open and vulnerable to their presence, living the tension of hospitality and learning from difference demonstrate how we have already welcomed others and are responsible for them. 


\section{References}

Battiste, M. (2000). Reclaiming Indigenous voice and vision. Vancouver: UBC Press.

Battiste, M., \& Barman, J. (1995). First Nations education in Canada: The circle unfolds. Vancouver, B.C.: UBC Press.

Bauman, Z. (1993). Postmodern ethics. Oxford: Blackwell.

Berry, K. (2007). Exploring the authority of whiteness in education: An auto-ethnographic journey. In P. Carr \& D. Lund (Eds.), The great white north? Exploring whiteness, privilege and identity in education (pp. 19-32). Rotterdam: Sense Publishers.

Biesta, G. (2003). Learning from Levinas: A response. Studies in Philosophy and Education, 22, 61-68.

Blades, D. (2006). Levinas and an Ethics for Science Education. Educational Philosophy and Theory, 38(5), 647-664.

Blades, D., Johnston, J., \& Simmt, E. (2000). Cultural diversity and secondary school curricula: A report to the Canadian Race Relations Foundation (pp. 61). Edmonton: University of Alberta.

Britzman, D. (1998). Lost subjects, contested objects: Toward a psychoanalytic inquiry of learning. Albany: SUNY Press.

Chinnery, A. (2003). Aesthetics of surrender: Levinas and the disruption of agency in moral education. Studies in Philosophy and Education, 22, 5-17.

Cohen, R. (2000). Ethics and cybernetics: Levinasian reflections. Ethics and Information Technology, 2, 27-35.

Davis, C. (1996). Levinas: An introduction. Cambridge: Polity Press.

Derrida, J. (1999). Adieu to Emmaneul Levinas (P.-A. Brault \& M. Nass, Trans.). Stanford: Stanford University Press.

Egéa-Kuehne, D. (Ed.). (2008). Levinas and education: At the intersection of faith and reason (Vol. 18). New York: Routledge.

Ermine, W. (2007). The ethical space of engagement. Indigenous Law Journal, 6(1), 193-203.

Hutchens, B. (2004). Levinas: A guide for the perplexed. London: Continuum.

Kumashiro, K. (2000). Toward a theory of anti-oppressive education. Review of Educational Research, 70(1), 25-53.

Kumashiro, K. (2001). "Posts" perspectives on anti-oppressive education in social studies, English, mathematics, and science classrooms. Educational Researcher, 30(3), 3-12.

Labelle, T., \& Ward, C. (1994). Multiculturalism and education: Diversity and its impact on schools and society. Albany: State University of New York Press.

Levinas, E. (1961). Totality and infinity. Pittsburgh: Dusquense.

Levinas, E. (1981). Otherwise than being: Or beyond essence (A. Lingis, Trans.). Pittsburgh: Dusquense.

Levinas, E. (1987). Time and the other and additional essays (R. A. Cohen, Trans.). Pittsburgh: Dusquesne University Press.

Levinas, E. (2000). God, death and time (B. Bergo, Trans.). Stanford: Stanford University Press. 
MacIntosh, P. (1998). White privilege: Unpacking the invisible knapsack. In P. Rothenberg (Ed.), Race, class, and gender in the United States: An integrated study (pp. 165-169). New York: St. Martin's Press.

Richardson, L. (2003). Poetic representation of interviews. In J. Gubrium \& J. Holstein (Eds.), Postmodern interviewing (pp. 187-201). London: Sage Publications.

Sparkes, A. (2002). Telling tales in sport and physcial activity: A qualitative journey. Champaign, IL: Human Kinetics.

St. Denis, V. (2009). Acknowledging the past and present-Aboriginal education, "Redefining Educational Problems and Solutions". In V. St. Denis, J. Silver, B. Ireland, P. George(Ningwakwe) \& R. Bouvier (Eds.), Reclaiming the learning spirit: Learning from our experience (Roundtable Report 2008) (pp. 13-34). Saskatoon: University of Saskatchewan, Aboriginal Education Research Centre (Saskatoon)

Standish, P. (2008). Levinas and the language of the curriculum. In D. Egea-Kuehne (Ed.), Levinas and education: At the intersection of faith and reason (Vol. 18, pp. 56-66). New York: Routledge.

Todd, S. (2001). 'Bringing more that I contain': Ethics, curriculum and the pedagogical demand for altered egos. Journal of Curriculum Studies, 33(4), 431-450.

Todd, S. (2003). Learning from the other: Levinas, pyschoanalysis, and ethical possibilities in education. Albany: State University of New York.

Todd, S. (2005). Welcoming and difficult learning: Reading Levinas with education (pp. 129): Unpublished.

Todd, S. (2007). Teachers judging without scripts, or thinking cosmopolitan. Ethics and Education, 2(1), 25 - 38.

Todd, S. (2008). Welcoming and Difficult Learning: Reading Levinas with education. In D. Egea-Kuehne (Ed.), Levinas and education: At the intersection of faith and reason (pp. 171-185). New York: Routledge.

White, M. (2010). Students are not to blame: Understanding the structural causes of family poverty. Our Schools / Our Selves, 19(2), 113-127.

\section{Endnotes}

${ }^{1} \mathrm{~A}$ found poem is a collection of words and phrasings of a person compiled by the writer to convey particular meanings found in the words of that person (Richardson, 2003; Sparkes, 2002).

2 "The face may be a real part of the human body available to be encountered, seen and experienced; but for Levinas face is before the alterity that presents itself to me, and as such face lies outside and beyond what can be seen or experienced” (Davis, 1996, p. 135). The concept of "face" is important for Levinas for when we encounter the face of the Other, the Other's face looks back at me as both witness and judge. The face is more than physical, referring to the uncontainable uniqueness, difference and freedom found in the reality of another person.

${ }^{3}$ Quotes and phrases attributed to Faith are taken from transcripts of interviews with Faith or from writings that she has given me permission to share. They appear in italics or in block quotes 
${ }^{4}$ Cheque day is a term used by some groups that indicate the day of the month when social assistance money is made available to families living below the Low Income Cut-Off. Often students miss school so as to be on hand to ensure they receive a portion of this money, otherwise they may find themselves without enough money for basic necessities for themselves, their families or their children.

${ }^{5}$ A Cree term for grandmother used in reference to family members but also others who are trusted and respected for their experience and wisdom. 